\title{
Pembentukan Karakter Wirausaha Anak Panti Asuhan Aisyiyah Dinoyo Malang melalui Batik Celup
}

\author{
Tutut Indria Permana ${ }^{1 *}$, Siti Mariyatul Qibtiyah², Ladysyah Fitri Rohmah ${ }^{3}$, Nur Hadi \\ Hidayat ${ }^{4}$, Hanifa Rizky Rahmawati ${ }^{5}$, Yeni Setyaningsih ${ }^{6}$, Aning Rochani ${ }^{7}$ iD \\ 1,2,3,4,5,6 Pendidikan Biologi FKIP Universitas Muhammadiyah Malang, Indonesia \\ ${ }^{7}$ Panti Asuhan Putri Aisyiyah Dinoyo Malang, Indonesia \\ *Corresponding author: tutut.indria@umm.ac.id
}

\begin{abstract}
Abstrak
Penanaman karakter wirausaha sejak dini dinilai penting untuk menciptakan karakter wirausahawan yang kreatif dan inovatif, terutama pada anak-anak panti asuhan seperti di Panti Asuhan Aisyiyah Dinoyo. Kondisi finansial panti asuhan yang tidak menentu menyebabkan anak-anak panti harus membantu menambah income panti sekaligus sebagai tabungan pribadi. Oleh sebab itu program PKM-M ini bertujuan untuk membentuk karaker wirausaha anak Panti Asuhan Aisyiyah dengan memberikan pelatihan pembuatan batik celup. Pelaksanaan program dilakukan secara daring menggunakan platform WhatsApp dan GoogleMeet. Materi pelatihan diberikan dalam bentuk video tutorial dan buku pedoman yan diberikan secara daring kepada mitra. Kegiatan pelatihan terdiri dari empat kegiatan daring. Hasil kegiatan PKM-M menunjukkan bahwa mitra telah mendapatkan wawasan baru terkait pembuatan batik celup dan cara pemasarannya. Selain itu program ini juga memberikan tahapan dasar untuk merintis usaha kecil yang bias dilakukan dari hasil produk batik celup.
\end{abstract}

Kata Kunci: Batik Celup, Karakter Wirausaha

\section{Abstract}

Instilling entrepreneurial character from an early age is considered important to create creative and innovative entrepreneurial characters, especially in orphanages such as the Aisyiyah Dinoyo Orphanage. The unstable financial condition of the orphanage causes the orphans to have to help increase the orphan's income as well as personal savings. Therefore, the PKM-M program aims to form the entrepreneurial character of the Aisyiyah Orphanage children by providing training to make dyed batik. Implementation of the program is carried out online using the WhatsApp and GoogleMeet platforms. Training materials are provided in the form of video tutorials and handbooks that are given online to partners. The training activities consist of four online activities. The results of the PKM-M activity show that partners have gained new insights regarding the manufacture of dyed batik and how to market it. In addition, this program also provides basic stages for starting a small business that can be done from the results of dyed batik products.

Keywords: Tie-Dye Batik, Entrepreneur Character

\section{Introduction}

Kemajuan ekonomi sebuah negara sangat dipengaruhi dari jumlah wirausahaawan. Adanya wirausaha akan mengurangi beban pemerintah terhadap jumlah penganguran yang ada disebuah Negara (Indriyani \& Subowo, 2019). Wirausaha juga diartikan sebagai orang yang memindahkan sumber-sumber ekonomi dari daerah dengan produktivitas rendah ke daerah dengan produktivitas dan hasil lebih tinggi (Nuryanto et al., 2020). Wirausaha adalah

$\begin{array}{lll}\text { History: } & & \text { Publisher: Undiksha Press } \\ \text { Received } & : \text { 23 November } 2020 & \text { Licensed: This work is licensed under } \\ \text { Revised } & : \text { 09 Desember } 2020 & \text { a Creative Commons Attribution 3.0 License } \\ \text { Accepted } & : \text { 15 Januari } 2021 & \text { CC O) OP } \\ \text { Published } & : \text { 25 Februari } 2021 & \end{array}$


kemampuan untuk mengelola suatu aktivitas usaha yang memiliki kemampuan dalam menggunakan sumber daya finansial, bahan mentah dan tenaga kerja untuk menghasilkan sesuatu yang baru (Halimah et al., 2018). Wirausaha memiliki karakter utama kreatif dan inovatif (Yusuf et al., 2019). Oleh sebab itu, menjadi wirausahawan bukan hal yang mudah dibutuhkan minat. Dengan minat yang tinggi, maka akan terdorong untuk mempelajari pengetahuan yang berkaitan dengan wirausahaan lebih serius (Kurniawan et al., 2016; Sari \& Rahayu, 2020). Minat wirausaha berasal dari dalam diri seseorang untuk menciptakan sebuah bidang usaha(Wiwin et al., 2017). Selain minat diperlukan juga motivasi dalam menciptakan sebuah usaha. Motivasi berwirausaha merupakan suatu dorongan yang timbul dari dalam diri seseorang untuk melakukan tindakan, termasuk menjadi young entrepreneur (Fatimah \& Purdianto, 2020). Motivasi akan berdampak terhadap kesuksesan dalam dunia wirausaha (Rosid et al., 2020).

Namun, kondisi saat ini rasio jumlah wirausahawan di Indonesia saat ini baru mencapai 2 persen dari total penduduk. Idealnya, rasio wirausahawan adalah 4 persen agar mampu mendorong pertumbuhan ekonomi nasional. Rendahnya jumlah wirausahawan di Indonesia ini disebabkan masyarakat, terutama generasi muda, lebih cenderung menjadi job seeker bukan job creation. Generasi muda saat ini memang kurang tertarik dengan dunia wirausaha, mereka memiliki alasan yang beragam seperti dunia wirausaha penuh tantangan, resiko, dan rentan kerugian (Yuliandari, 2020) serta lemahnya motivasi untuk memunculkan ide-ide kreatif dalam menciptakan sebuah peluang usaha. Lemahnya motivasi generasi muda ini perlu diperbaiki dengan memberdayakan jiwa wirausaha sejak dini.

Pendidikan mengambil peranan utama untuk menanamkan karakter wirausaha pada seorang individu (Agustina, 2017; Arita et al., 2020; Ganefri, 2013; Hidayat et al., 2018; Suprapto, 2018). Sehingga, persiapan jiwa wirausaha sejak dini sangat dibutuhkan agar kedepannya mampu menunjang perekonomian sendiri. Ketika seorang pendidik mengajarkan kewirausahaan sejak usia belia, maka ketika dewasa mereka akan memiliki masa depan yang baik dan tumbuh menjadi pribadi yang kreatif (Arita et al., 2020; Farida et al., 2017; Ganefri, 2013). Kewirausahaan yang dilakukan oleh seseorang tidak ada patokan dari segi usia (Sukirman, 2017). Oleh sebab itu penanaman karakter wirausaha sejak dini dinilai penting untuk menciptakan karakter wirausahawan yang kreatif dan inovatif, terutama pada anak-anak panti asuhan.

Anak-anak panti asuhan harus mandiri dalam memenuhi kebutuhan hidup tanpa bergantung pada keberadaan orang tua. Hal ini nampak pada hasil observasi yang dilakukan di Panti Asuhan Aisyiyah Dinoyo Kota Malang yang menunjukkan bahwa pendapatan finansial untuk memenuhi kebutuhan anak-anak panti asuhan diperoleh dari sumbangan para donatur. Namun demikian sumbangan donatur ini tidak dapat diprediksi pada setiap bulannya. Fakta ini menjadi masalah utama panti asuhan yang belum bisa dipecahkan. Oleh sebab itu perlu pemberdayaan anak-anak panti asuhan untuk mengembangkan keterampilan berwirausaha sebagai alternatif solusi dalam menghadapi masalah tersebut. Selain sebagai sumber pemasukan dalam segi ekonomi, hal ini juga bisa melatih anak-anak panti untuk memiliki mental kuat dan menjadi pribadi yang kreatif. Hasil wawancara dangan pihak pengurus Panti Asuhan Aisyiyah Dinoyo Kota Malang menyebutkan bahwa selama ini belum ada kegiatan yang mengarah pada wirausaha yang dilakukan di panti. Sehingga kami memberikan alternatif solusi yakni pelatihan pembuatan batik celup sebagai upaya pemberdayaan anak panti dalam pembentukan karakter wirausaha. Batik celup merupakan cara pembuatan batik dalam kategori mudah yang dapat dilakukan oleh siapa pun, terutama anak-anak usia muda. Sebagian besar anak-anak Panti Asuhan Aisyiyah Dinoyo Kota Malang adalah anak SMP (Sekolah Menengah Pertama). Pelatihan pembuatan batik celup ini akan memberikan motivasi pada anak-anak tersebut. 
Program pelatihan dilakukan dengan cara daring melalui pertemuan-pertemuan virtual melalui aplikasi zoom meeting dan google meet. Hal ini dilakukan karena kondisi di masa pandemi yang tidak memungkinkan untuk melakukan pelatihan secara langsung. Program pelatihan pembuatan batik celup harapannya menjadikan anak di Panti Asuhan Aisyiyah Dinoyo Kota Malang menjadi mandiri dan kreatif dalam berkarya meskipun tanpa pembinaan orang tua kandungnya. Selanjutnya hasil produksi batik celup ini dapat dikembangkan menjadi berbagai produk yang diharapkan dapat memiliki nilai jual, sehingga anak-anak di Panti Asuhan Aisyiyah Dinoyo Kota Malang dapat berwirausaha mandiri dan dapat memberikan alternatif income untuk panti. Dengan demikian akan terbentuk wirausaha baru dari anak-anak panti asuhan.

\section{Materials and Methods}

Kegiatan PKM-M dilakukan di Panti Asuhan Putri Aisyiyah Dinoyo Malang yang berada di Jl. Mayjend. Mt. Haryono Gang III No. 231 A, Dinoyo, Kec. Lowokwaru, Kota Malang, Jawa Timur 65145. Program ini dilaksanakan secara intensif (tetap) dan insidental (tidak tetap) setiap minggunya dan pelaksanaanya disesuaikan dengan kondisi dan keadaan dari pada sasaran yang ada sebagai lembaga atau organisasi sosial dan keagamaan. Panti Asuhan Putri Aisyiyah Dinoyo merupakan panti asuhan yang menolong anak yatim yang memiliki latar belakang kehidupan sebagai anak yatim, piatu, yatim piatu, dan du'afa terutama mereka tinggal di daerah perdesaan. Mayoritas anak-anak ini kurang akses pendidikan, memiliki latar belakang keluarga yang bermasalah, dan kurang mampu dalam kondisi ekonomi. Tingkat pendidikan anak-anak yang tinggal di Panti Putri Aisyiyah Dinoyo berkisar antara SD sampai dengan SMA, namun didominasi oleh anak usia SMP. Panti Asuhan Putri Aisyiyah Dinoyo memiliki masalah terkait income yang tidak pasti setiap bulannya, sebagian besar bersumber dari donator. Ada kegiatan wirausaha yang dilakukan oleh pengurus panti dengan memproduksi kue basah. Namun belum ada kegiatan wirausaha yang dilakukan oleh anak-anak panti. Anak-anak Panti Asuhan Putri Aisyiyah Dinoyo Malang yang menjadi mitra PKM-M memiliki keinginan untuk membantu income panti dan ingin memiliki tabungan mandiri. Namun mereka belum memiliki keterampilan berwirausaha. Masalah ini timbul karena kurangnya tenaga tutor yang mengajar atau memberikan pelatihan. Berdasarkan latar belakang kehidupan anak Panti Asuhan Putri Aisyiyah Dinoyo, mereka memerlukan keterampilan untuk kehidupan selanjutnya setelah purna asuh dari Panti Putri Aisyiyah Dinoyo, sehingga para remaja putri panti dapat memulai kehidupan di masyarakat dengan dibekali keterampilan untuk berwirausaha dengan pembuatan batik celup yang dapat meningkatkan terpenuhinya kebutuhan secara finansial.

Sasaran mitra dari PKM-M ini ditunjukkan kepada pada 10 orang anak remaja putri di Panti Asuhan Putri Aisyiyah Dinoyo. Anak anak ini hanya mendapatkan pendidikan formal dari sekolahnya, sehingga sebagian waktu yang luang digunakan untuk bermain. Maka dari itu dengan adanya pelatihan pembuatan batik celup ini diharapkan dapat menghasilkan produk yang memiliki nilai jual untuk meningkatkan tabungan finansial, dan menjadikan anak anak yang bermasa depan baik. Kegiatan PKM-M dilaksanakan dengan tahapan yang dijabarkan sebagai berikut: Pertama, tahap koordinasi persiapan program. Tahap persiapan ini dilakukan dengan meminta persetujuan kepada Kepala Panti Asuhan Putri Aisyiyah Malang untuk memastikan kesediaan pihak panti dalam melakukan kegiatan pelatihan batik celup secara daring bersama dengan mitra sejumlah 10 anak. Kedua,tahap pembuatan video tutorial dan buku pedoman. Video tutorial yang diberikan kepada mitra sebagai sarana pelatihan pembuatan batik celup secara daring dibuat menggunakan bantuan software Kinemaster. Software Kinemaster memiliki banyak efek yang bisa membuat video animasi. Buku Pedoman Pelaksanaan Program dibuat menggunakan bantuan software Power Point. Ketiga, tahap pelatihan secara daring. Kegiatan dilaksanakan setiap satu minggu sekali pukul 
13.00 WIB yang dimulai pada tanggal 22 Agustus 2020 - 15 September 2020. Pelaksanaan kegiatan melalui platform Google Meet dan WhatsApp grup yang dilakukan dengan metode ceramah dan tanya jawab. Pada tahap penyampaian materi anak-anak panti asuhan diberikan video tutorial cara pembuatan batik celup dan buku pedoman pelaksanaan untuk menunjang pemahaman anak-anak panti dalam proses transfer ilmu. Kegiatan berisi mengenai materi tentang kewirausahaan, tata cara pembuatan batik celup cara pengemasan dan pemasaran produk batik celup

\section{Results and Discussion}

Hasil kegiatan PKM-M yang dilakukan di Panti Aisyiyah Panti Asuhan Putri Aisyiyah Dinoyo dijabarkan sebagai berikut: Pertama, Hasil Koordinasi Persiapan Program. Kegiatan koordinasi persiapan program dilakukan bersama mitra dengan melakukan pertemuan online melalui Google Meet (Gambar 1). Kegiatan ini berisi permohonan ijin untuk melakukan pelatihan secara daring dan menetapkan jadwal pelatihan yang dilakukan bersama mitra (10 anak panti asuhan). Jadwal pelatihan daring dilakukan secara rutin agar anak-anak panti terbiasa dan mereka mampu memahami materi yang disampaikan. Seperti penjelasan (Sukirman, 2017) bahwa jiwa kewirausahaan akan muncul ketika ada pembiasaan pada individu.

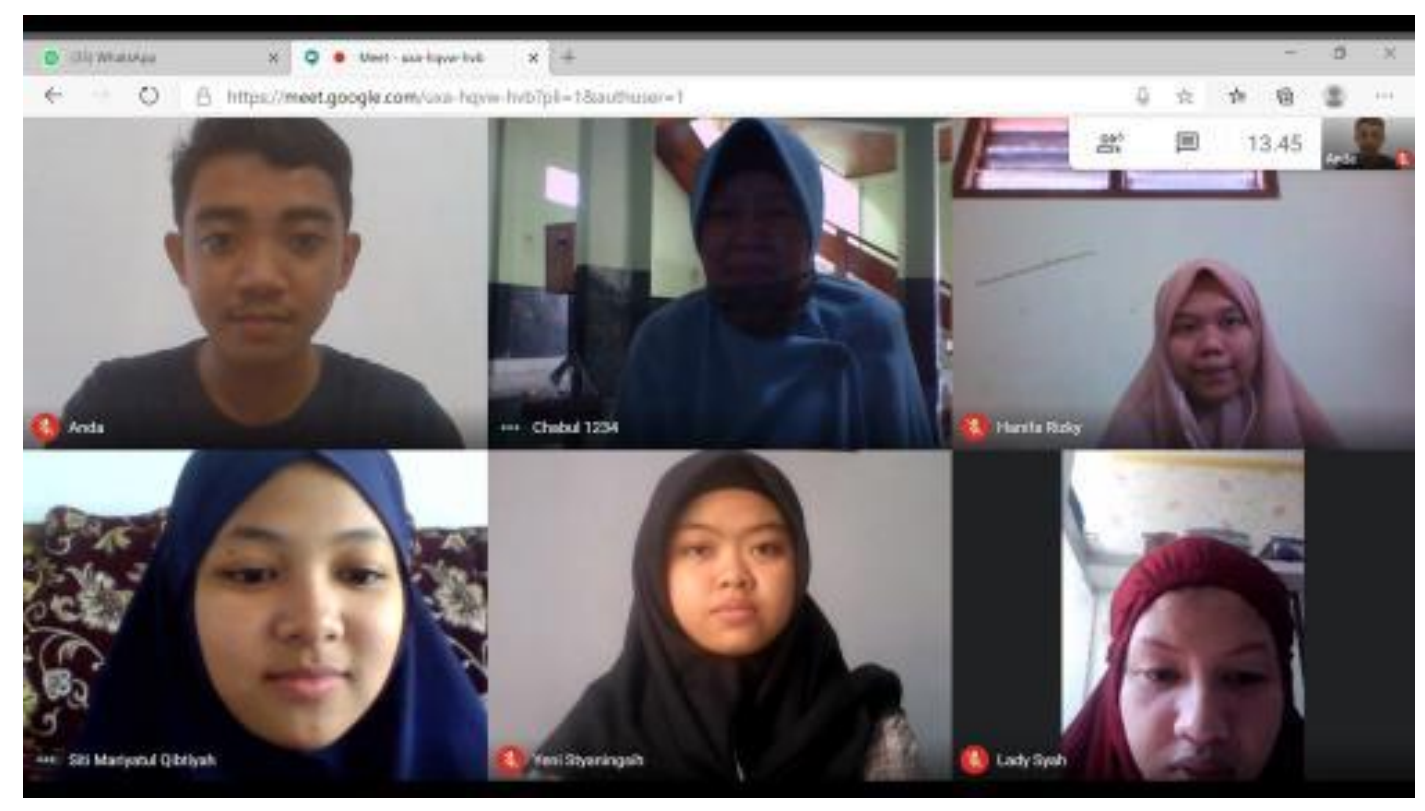

Gambar 1. Dokumentasi kegiatan koordinasi persiapan program bersama mitra melalui Google Meet

Kedua, hasil pembuatan video tutorial dan buku pedoman. Upaya yang dilakukan untuk mempermudah mitra dalam memahami proses pembuatan batik celup adalah dengan membuat video tutorial menggunakan software Kinemaster. Tahapan pembuatan video tutorial dijelaskan pada Gambar 2. Hasil video tutorial diupload di Youtube dengan link https://youtu.be/hrCjw7hWHgk. Selanjutnya buku Pedoman Pelaksanaan Program (Gambar 3) dibuat menggunakan bantuan software Power Point. Buku pedoman ini diberikan kepada mitra melalui email dan pesan WhatsApp. Materi yang ada dalam buku pedoman berisi tentang tata cara pembuatan batik celup, cara produksi, cara pengemasan, cara pemasaran dan cara pembukuan usaha kecil. Namun ketika penyampaian materi mitra diberi kesempatan untuk berkreasi menggambar pola-pola batik selain contoh yang ada di buku pedoman. 


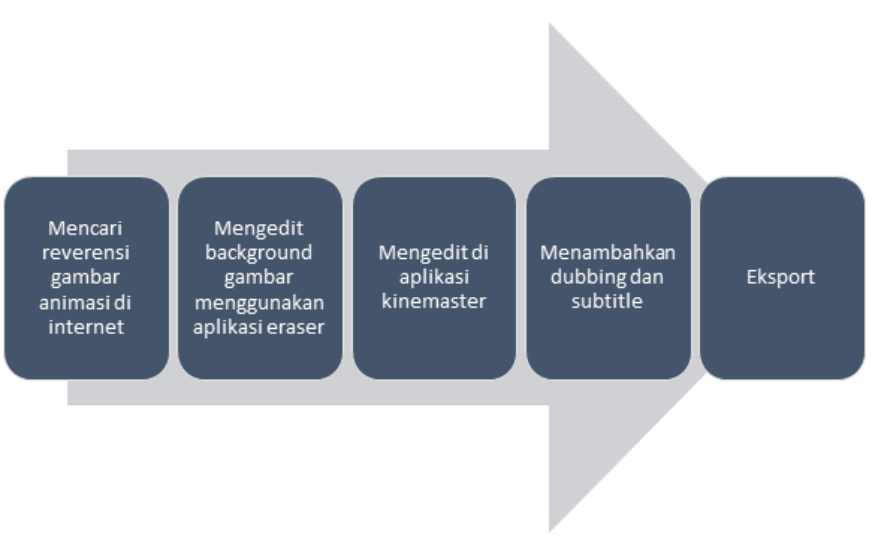

Gambar 2. Tahap pembuatan video tutorial

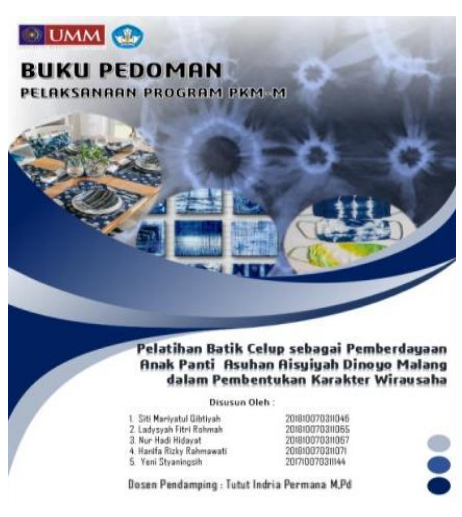

Gambar 3. Sampul depan buku pedoman pelaksanaan program PKM-M

Ketiga, kegiatan pelatihan secara daring. Kegiatan koordinasi dan pelatihan daring bersama mitra sasaran dilakukan sebanyak empat kali pertemuan (Gambar 4). Pertemuan pertama tim PKM-M memberikan materi awal yang berisi pengenalan batik celup secara umum kepada mitra, Pertemuan kedua dilakukan diskusi daring bersama mitra dengan meilhat video tutorial yang ada di Youtube. Mitra memperhatikan apa saja alat dan bahan yang dibutuhkan dalam pembuatan batik celup. Pada pertemuan ini juga dilakukan tanya jawab langsung terkait materi yang disampaikan.

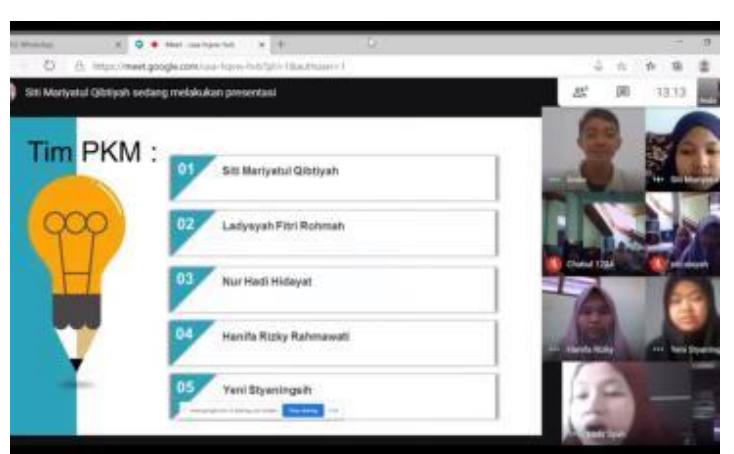

(a)

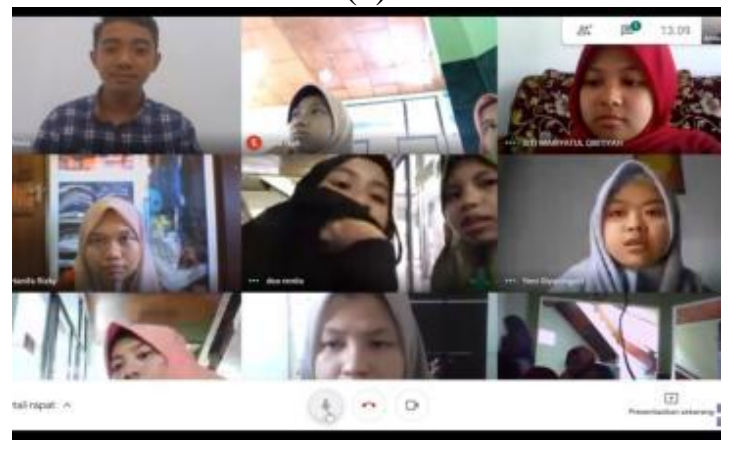

(c)

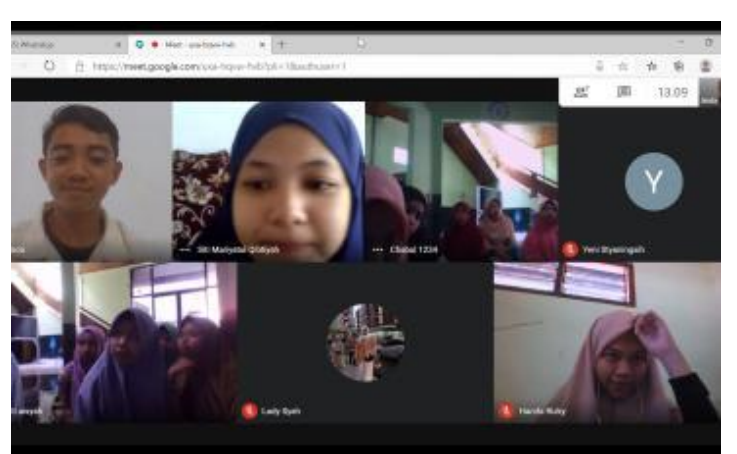

(b)

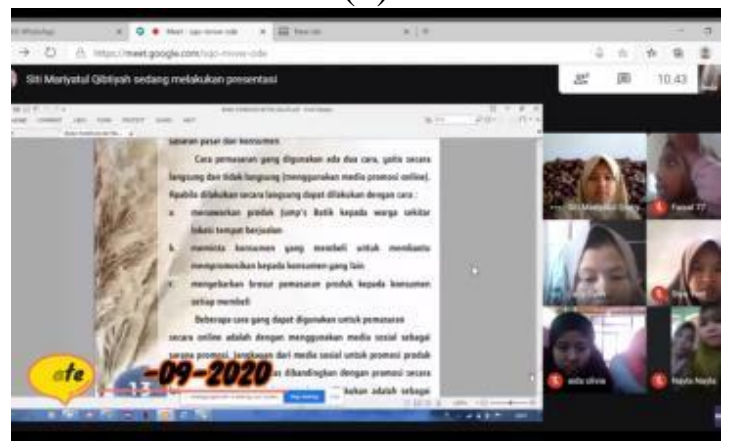

(d)

Gambar 4. Dokumentasi kegiatan pelatihan secara daring di pertemuan pertama (a), kedua (b), ketiga (c), dan keempat (d)

Pertemuan berikutnya tim PKM-M bersama mitra mengamati dan berdiskusi buku panduan pembuatan batik celup yang sudah dibagikan melalui pesan WhatsApp. Dalam buku panduan dijelaskan berbagai pola batik dan beberapa contoh produk yang bisa dibuat dari hasil kain batik celup. Selain itu mitra juga diberikan kesempatan untuk membuat pola-pola 
batik sesuai kreasi dan inovasi mereka. Hal ini penting dilakukan untuk menumbuhkan jiwa kewirausahaan dalam diri mitra. Kegiatan pembelajaran kewirausahaan dapat dilakukan denan efektif ketika siswa membuat produk sendiri (Hidayat et al., 2018). Produk dalam tahap ini berupa pola-pola batik celup beserta jenis produk yang diusulkan oleh anak-anak panti asuhan. Ketrampilan berkreasi dan inovasi ini menjadi karakter wirausaha yang penting (Arita et al., 2020; Harnani, 2020; Saragih, 2017; Yusuf et al., 2019). Karater wirausaha berpengaruh terhadap kesuksesan usaha (Indarto \& Santoso, 2020). Karakter wirausaha menjadi faktor penentu yang mempengaruhi keberhasilan usaha (Arita et al., 2020; Indarto \& Santoso, 2020). Seorang wirausahawan dituntut selalu optimis dan berpikiran positif dan kreatif untuk menghadapi segala keadaan dalam lingkungan usaha yang sangat dinamis (Ganefri et al., 2017; Indarto \& Santoso, 2020).

Selanjutnya pada pertemuan terakhir diberikan materi terkait pengemasan (packaging) dan pemasaran produk batik celup. Pengemasan ini juga menuntut kreatifitas mitra untuk dapat menarik pembeli. Sehingga diakhir materi diharapkan mitra bisa memunculkan ide inovasi mereka terhadap pengemasan produk yang akan dijual. Materi pemasaran juga didiskusikan bersama mitra, tim PKM-M memberikan usulan untuk melakukan pemasaran secara offline dan online. Pemasaran online bisa dilakukan dengan membuka online shop dengan memanfaatkan applikasi Instagram dan Shopee. Kegiatan pelatihan yang dilakukan sebagai upaya untuk menanamkan karakter wirausaha pada anak-anak Panti Asuhan Putri Dinoyo Malang. Seperti Karakter wirausaha berupa kreatif dan inovatif menjadi karakter dasar yang harus dimiliki untuk mencipatkan peluang usaha (Indarto \& Santoso, 2020; Yusuf et al., 2019). Sebagai upaya keberlanjutan program PKM-M akan dilakukan pendampingan secara langsung ketika pandemi COVID-19 sudah berakhir.

\section{Conclusion}

Kegiatan PKM-M pelatihan pembuatan batik celup secara daring kepada anak Panti Asuhan Putri Aisyiyah Dinoyo Malang telah terlaksana dan mendapat respon baik. Mitra telah mendapatkan pengetahuan terkait cara produksi, pengemasan dan pemasaran batik celup yang bisa dijadikan alternatif wirausaha. Pendampingan langsung dalam pembuatan hingga produksi batik celup secara luring akan dilaksanakan setelah pandemi berakhir sebagai upaya keberlanjutan program PKM-M.

\section{Acknowledgement}

Terimakasih kepada Direktorat Pembelajaran dan Kemahasiswaan Dikti Kemendikbud RI atas pendanaan yang diberikan pada Program Kreativitas Mahasiswa skim PKM-M dengan No. Kontrak: 1381/SPPK/LL7/KM/2020 sehingga program ini dapat terlaksana dengan baik

\section{References}

Agustina, D. A. (2017). Model pembelajaran untuk mengenalkan kewirausahaan pada siswa sekolah dasar kelas rendah. Bangun Rekaprima, 03(2), 43-56.

Arita, S., Evanita, S., \& Syofyan, R. (2020). Pengembangan karakter wirausaha dalam pelajaran ekonomi bagi guru ekonomi di Kota Padang. Jurnal Ecogen, 3(2), 294-298. https://doi.org/10.24036/jmpe.v3i2.8941.

Farida, E., Djatmika, E. T., Siswoyo, B. B., \& Witjaksono, M. (2017). Pengembangan model pembelajaran kewirausahaan berbasis proyek untuk menumbuhkan semangat wirausaha mahasiswa Prodi Pendidikan Ekonomi IKIP PGRI Bojonegoro. JPEK (Jurnal Pendidikan Ekonomi Dan Kewirausahaan), 1(1), 8-18. https://doi.org/10.29408/jpek.v1i1.461. 
Fatimah, S. E., \& Purdianto, A. (2020). Model Determinasi Minat Beriwirausaha Mahasiswa. Jurnal Inspirasi Bisnis Dan Manajemen, 4(1), 57. https://doi.org/10.33603/jibm.v4i1.2569.

Ganefri. (2013). The development of production-based learning approach to entrepreneurial spirit for engineering students. Asian Social Science, 9(12 SPL ISSUE), 162-167. https://doi.org/10.5539/ass.v9n12p162.

Ganefri, Hidayat, H., Kusumaningrum, I., \& Mardin, A. (2017). Needs analysis of entrepreneurships pedagogy of technology and. vocational education with production base learning approach in higher education. International Journal on Advanced Science, Engineering and Information Technology, 7(5), 1701-1707. https://doi.org/10.18517/ijaseit.7.5.1510

Halimah, S., Wanto, H., \& Mahmu'ddin, M. (2018). Menumbuhkan Minat Berwirausaha Mahasiswa Melalui Kecerdasan Emosional. Jurnal Studi Agama Dan Masyarakat, 14(1), 53. https://doi.org/10.23971/jsam.v14i1.870.

Harnani, N. (2020). Model pembelajaran kewirausahaan kreatif melalui praktek usaha dalam menumbuhkan kreatifitas dan inovatif mahasiswa. Sosiohumaniora, 22(1), 79-87. https://doi.org/10.24198/sosiohumaniora.v22i1.24510.

Hidayat, H., Herawati, S., Hidayati, A., \& Syahmaidi, E. (2018). Pembelajaran kewirausahan dengan pendekatan berbasis produksi sebagai alternatif mempersiapkan lulusan berkualitas di pendidikan tinggi. Seminar Nasional Pakar Ke 1, 123-.

Indarto, \& Santoso, D. (2020). Karakteristik wirausaha, karakteristik usaha dan lingkungan usaha penentu kesuksesan usaha mikro kecil dan menengah. Jurnal Riset Ekonomi Dan Bisnis, 13(1), 54-69.

Indriyani, I., \& Subowo. (2019). Pengaruh Pengetahuan Kewirausahaan dan Lingkungan Keluarga Terhadap Minat Berwirausaha Melalui Self-Efficacy. Economic Education Analysis Journal, 2(1), 18-23. https://doi.org/10.15294/eeaj.v8i2.31493.

Kurniawan, A., Khafid, M., \& Pujiati, A. (2016). Pengaruh Lingkungan Keluarga, Motivasi, dan Kepribadian Terhadap Minat Wirausaha Melalui Self Efficacy. Journal of Economic Education, 5(1), 100-109.

Nuryanto, U. W., Mz, M. D., Sutawijaya, A. H., \& Saluy, A. B. (2020). Analisis Pengaruh Sikap Norma Subjektif Efikasi Diri Dan Kecerdasan Emosi Terhadap Minat Wirausaha. Dynamic Management Journal, https://doi.org/10.31000/dmj.v4i1.2509.

Rosid, A., Hafidiah, A., Yuniarti, Y., \& Abdurrohim, D. (2020). Peningkatan Motivasi Kewirausahaan Para Pelaku Usaha di Desa Warnasari Kecamatan Pangalengan Kabupaten Bandung. Kaibo Abhinaya: Jurnal Pengabdian Masyarakat, 2(2). https://doi.org/https://doi.org/10.30656/ka.v2i2.2061.

Saragih, R. (2017). Membangun usaha kreatif, inovatif dan bermanfaat melalui penerapan kewirausahaan sosial. Jurnal Kewirausahaan, 3(2), 26-34.

Sari, B., \& Rahayu, M. (2020). Pengaruh Lingkungan, Pendidikan Kewirausahaan dan Penggunaan E-commerce pada Peningkatan Minat Berwirausaha Mahasiswa FEB UPI YAI. Jurnal IKRA-ITH Ekonomika, 2(3), 20-29. https://journals.upiyai.ac.id/index.php/IKRAITH-EKONOMIKA/article/download/558/414/.

Sukirman, S. (2017). Jiwa kewirausahaan dan nilai kewirausahaan meningkatkan kemandirian usaha melalui perilaku kewirausahaan. Jurnal Ekonomi Dan Bisnis, 20(1), 117. https://doi.org/10.24914/jeb.v20i1.318.

Suprapto, H. A. (2018). Strategi pembelajaran kewirausahaan berbasis Teknologi Informasi (T.I) terhadap peningkatan minat mahasiswa menjadi wirausaha. Didaktis: Jurnal Pendidikan Dan Ilmu Pengetahuan, 18(1), 61-73.

Wiwin, N., Tati, S., \& Rahmawati, Y. (2017). Minat Berwirausaha Mahasiswa Program Studi 
Pendidikan Tata Boga Universitas Pendidikan Indonesia. Media Pendidikan, Gizi, Dan Kuliner, $6(2)$,

81-93. https://ejournal.upi.edu/index.php/Boga/article/download/9030/5624.

Yuliandari, N. K. (2020). Pendekatan Tri Hita Karana Dalam Meningkatkan Motivasi Berwirausaha Mahasiswa. Jurnal Manajemen Bisnis, 17(1), 118. https://doi.org/10.38043/jmb.v17i1.2346.

Yusuf, A., Suminar, T., \& Kisworo, B. (2019). Karakter kewirausahaan mahasiswa. Journal of Nonformal Education and Community Empowerment, 3(2), 139-147. https://doi.org/10.15294/pls.v2i1.23448. 